\title{
The Association among Leader-member Exchange, Work-to-family Enrichment and Organization Identification
}

\author{
Dong-mei MA ${ }^{1}$ and Lin QIU ${ }^{2, *}$ \\ ${ }^{1}$ School of Applied Foreign Languages Guangdong Teachers College of Foreign \\ Language and Arts, Guangzhou, China \\ ${ }^{2}$ School of Business Administration, South China University of Technology, Guangzhou, \\ China \\ ${ }^{*}$ Corresponding author, E-mail: linqiu@scut.edu.cn
}

Keywords: Leader-member exchange, Work-to-family enrichment, Organization identification.

\begin{abstract}
This study examined a model that links leader-member exchange (LMX) relationship and employee organization identification (OID) through the mediating mechanism of work-to-family enrichment (WFE). Data from a sample of 179 employed working adults in China demonstrated that LMX was positively related to both WFE and OID. LMX and WFE were negatively related to OID. And WFE partially mediated the relationship between LMX and OID. Implications for research and practice are discussed.
\end{abstract}

\section{Introduction}

Despite the majority of research on work-family interface has focused on work-family conflict, scholars have increased their interest in examining how involvement in one role positively influences the other role - work-family enrichment, the extent to which experiences in one role (work or family) improve the quality of life in the other role [1]. This emerging focus is important because it supplements the dominant conflict perspective in work-family literature and provides us a complete understanding of the complex work-family relationships. However, more research is needed to understand the antecedents and consequences of enrichment.

The current study has the following purposes. The first purpose is to extend the knowledge of work-family enrichment by examining the leader-member exchange (LMX) relationship as a potential antecedent variable. Some studies have examined the effects of supervisor support on work-family enrichment (c.f. Tang et al., 2014). However, very few attempts have been developed to examine LMX as an antecedent of work-family enrichment. Second, we examined organization identification (OID) as a outcome of work-family enrichment. According to Wayne et al. (2006), more research is needed on how enrichment is related to work-related outcomes to make the case to organizations that enrichment is important and deserves attention [2]. Last and most important, we proposed that work-to-family enrichment (WFE) may be a mediator in the relation between LMX and OID. To our knowledge, the mediating role of WFE in the relation between LMX and OID has also not been explored in the literature. 


\section{Literature Review and Hypotheses}

\section{Work-family Enrichment}

Role accumulation theory suggested that multiple-role participation could bring individuals a variety of rewards, such as greater role privileges, lower strain, and greater status. Expansionist approach argued that resources generated in one role domain could benefit a second role. More recently, Greenhaus and Powell (2006) expanded these findings and provided a comprehensive theoretical model of work-family enrichment, which proposes that enrichment occurs when resource gains in one role promote improved performance in another role [1]. Carlson et al. (2006) identified the bi-directional nature of work-family enrichment. That is, work may enrich family (i.e., work-to-family enrichment; WFE) and family may enrich work (i.e., family-to-work enrichment; FWE) [3]. The present research focuses on WFE because it has been believed that work-related variables influence WFE rather than FEW [4].

\section{LMX and WFE}

Greenhaus and Powell (2006) identified five types of resources that drive the work-family enrichment process, including skills and perspectives, psychological and physical resources, social-capital resources, flexibility, and material resources [1]. The resource relevant to the present study is the social capital - the resources derived from social relationships. The relationship between supervisors and their subordinates are often the most important workplace relationship for employees.

LMX refers to the quality of the supervisor-subordinate relationship [5]. Employees with high-quality LMX gain sponsorship from their supervisors and obtain salient organizational resources through supervisors' social network [6]. Compared with those in low-quality LMX relationships, employees in high-quality LMX relationships will obtain more job- or career-enhancing resources, such as more enriched work opportunities, autonomy, valuable information, social support or other socio-emotional interactions [7]. Thus, we propose the following hypothesis:

H1: LMX is positively related to WFE.

\section{WFE and OID}

As previously mentioned, to establish the importance of enrichment to organizations, it is necessary to link work-family enrichment with work-related outcomes. Thus, we examined the relation of work-family enrichment to OID. OID is defined as an employee's perception of oneness with or belongingness to the organization. Researchers have demonstrated that OID is positively related to individual and organizational performance [8].

WFE means experiences in work domain improve the quality of life in family [1]. According to social exchange theory, an organization's beneficial actions directed at employees create obligations for employees to reciprocate in positive ways. It is reasonable to suggest that employees will reciprocate the organization by identifying with it when they perceive the resources provided by the organization have enriched their family life. Thus, we propose the following hypothesis:

H2: WFE is positively related to OID. 


\section{LMX and OID: WFE as a Mediator}

Although LMX mainly describes the relationship within the supervisor-subordinate dyad, current research has continuously shown that high-quality LMX not only contributes to work outcomes pertinent to the vertical dyadic members but also to organizationally relevant attitudes including increased organizational commitment, job satisfaction, and decreased turnover intention [9].

Given that supervisor-subordinate relationship is the basic work unit within the organization and employees often view their supervisors as agents of the organization, the quality of LMX is crucial for employees' identification to their working organization [10]. Employees with high-quality LMX will be assigned important duties and responsibilities, and have better career development within the organization. On the contrary, employees with low-quality LMX receive less supervisory support and fewer advancement opportunities within the organization. Thus, it is logical to argue that employees with higher-quality LMX are more likely to experience oneness with their working organizations.

Hypothesis 3: LMX is positively related to OID

As previously mentioned, we were also interested in the mediating role of work-family enrichment in explaining the relation between LMX and OID. Thus far, we proposed LMX to be related to WFE and OID. Also, we proposed WFE to be related to OID. Therefore, it is reasonable to argue that the WFE can be an important mediating mechanism in the relationship between LMX and OID. That is, the high-quality LMX will facilitate employees' experience of WFE, which, in turn, enhances their OID. Thus, we propose the following hypothesis:

H4: WFE will mediate the positive relation between LMX and OID.

\section{Methods}

\section{Participants}

Questionnaires were distributed to part time graduate (MBA) students who were also full-time employees at a large university in South China. Although this study used a convenient sample, the diverse organizational and job characteristics of the participants are critical to maximize the range of the focal variables in the present study. One of the researchers visited all graduate classes and distributed questionnaires to participants. In total, 179 surveys were received. The sample comprised $41.9 \%$ male respondents, and $55.3 \%$ married or cohabited participants.

\section{Measurement}

All the measurements were rated on a 5-point scale that ranged from 1(strongly disagree) to 5 $=($ strongly agree $)$.

Work-to-family enrichment (WFE). WFE was measured using the 7-item scale developed by Tang et al. (2007) under the Chinese settings [11]. In the present study, Cronbach's $\alpha$ for WFE was .78.

Leader-member exchange (LMX). LMX was measured using the LMX-7, a unidimensional scale from Scandura and Graen, and Novak (1986) [12]. In the present study, Cronbach's $\alpha$ was .85 .

Organization identification (OID). OID was measured using the four-item scale from Carmeli, Gilat, and Waldman (2007) [13]. In the present study, Cronbach's $\alpha$ was .82. 
Control Variables. According to previous research, this study statistically controlled for age, marital status, and gender in all analyses to rule out alternative explanations for our findings.

\section{Results}

\section{Descriptive Statistics and Correlational Analyses}

Table 1. Descriptive statistics and correlational analys es

\begin{tabular}{|l|c|c|c|c|c|}
\hline & Mean & SD & LMX & WFE & OID \\
\hline Age & 1.48 & .75 & .03 & .00 & .17 \\
\hline Marital Status & .55 & .50 & -.06 & -.10 & .10 \\
\hline Gender & .42 & .50 & -.08 & -.02 & .07 \\
\hline LMX & 3.30 & .76 & 1.00 & & \\
\hline WFE & 3.83 & .59 & $.29^{* * *}$ & 1.00 & \\
\hline OID & 3.32 & .83 & $.19^{* *}$ & $.20^{* *}$ & 1.00 \\
\hline
\end{tabular}

Table 1 shows the means, standard deviations, and inter-correlations of all study variables. The $\mathrm{LMX}$ variable mean score $(\mathrm{M}=3.30, \mathrm{SD}=.76)$ shows that employees are fairly positive about the relationship with their supervisor. Furthermore, it is shown that employees experience fairly high WFE $(\mathrm{M}=3.83, \mathrm{SD}=.59)$ and high $\mathrm{OID}(\mathrm{M}=3.32, \mathrm{SD}=.83)$, which can be considered positive results. An examination of the zero-order correlations of the variables demonstrated that all of the study variables were correlated in the direction expected. LMX was positively related to both WFE $(\mathrm{r}=.29, \mathrm{p}<.001)$ and $\mathrm{OID}(\mathrm{r}=.19, \mathrm{p}<.01)$, and WFE was positively related to OID $(r=.20, \mathrm{p}<.01)$.

\section{Hypothesis testing}

We used hierarchical multiple regressions to test Hypotheses 1 - 4. In all analyses, we entered the control variables of gender, age and marital status first into the regression model, and then the primary study variables. Table 2 shows the regression results for estimated coefficients of the mediation model.

Table 2. Results of the hierarchical regression analys is

\begin{tabular}{|c|c|c|c|c|c|}
\hline & \multicolumn{2}{|c|}{ WFE } & \multicolumn{3}{|c|}{ OID } \\
\hline & M 1 & M 2 & M 3 & M 4 & M 5 \\
\hline Age & .04 & .03 & .16 & .14 & .14 \\
\hline $\begin{array}{l}\text { Marital } \\
\text { Status }\end{array}$ & -.12 & -.09 & .03 & .05 & .06 \\
\hline Gender & .00 & .02 & .06 & .07 & .07 \\
\hline LMX & & $.28^{* * * *}$ & & $.19^{*}$ & $.15^{*}$ \\
\hline WFE & & & & & $.17^{*}$ \\
\hline$\Delta \mathrm{R}^{2}$ & .01 & $.08^{* * * *}$ & .04 & $.04^{*}$ & $.03^{*}$ \\
\hline F & .66 & $4.35^{* *}$ & 2.10 & $3.30^{*}$ & $3.65^{* * *}$ \\
\hline
\end{tabular}

All coefficients reported are standardized betas. 
Baron and Kenny (1986) proposed a four-step approach to establish the conditions for mediation. As can be seen in Table 2, after controlling for several demographic variables, LMX was significantly related to WFE (Model $2 ; \beta=.28, \mathrm{p}<.001$ ). Thus, Condition (a) for the mediation effect was met. LMX was also significantly related to OID (Model $4 ; \beta=.19, p$ $<.05$ ), satisfying Condition (b). WFE was negatively related to OID (Model 5; $\beta=.17, p$ $<.05)$. Thus, Condition (c) was met. Further, after WFE was taken into account, the effect of LMX on OID remained significant but decreased in magnitude (Model $5 ; \beta=.15, \mathrm{p}<.01$ ), which suggests a partial mediation effect. Thus, Condition(d) was satisfied. To provide a more rigorous test of the mediation effect, we used Preacher and Hayes's (2004) macro to test the indirect effect with 5,000 bootstrap samples [14]. Results showed that the 95\% confidence interval of the indirect effect estimate $[.01, .11]$ did not contain zero, indicating that the indirect effect was significant. Taken together, Hypotheses 1-4 were supported, that is, WFE partially mediated the relationship between LMX and OID.

\section{Discussion}

These findings of this study make several important contributions to the literature. First, we found that LMX does appear to be an important antecedent of the WFE. Greenhaus and Powell (2006) suggest that resources are the key in the generation of enrichment. According the LMX theory, employees will be benefited from additional resources in high-quality relationships [7]. Therefore, a high-quality supervisor-subordinate relationship is an important resource which can facilitate WFE.

Second, the results of this study contribute to the existing literature by identifying OID as an important outcome of WFE. As an important employee-organization variable, OID is substantially associated with positive employee and organization outcomes [8]. By establishing the linkages between WFE and OID, the present study contributes to the work-family enrichment literature by answering recent calls to expand the list of work-related outcomes to show the significance of the positive work-family relationship [2].

Finally, the results of this study also add to our existing knowledge on the relationship between LMX and OID. Both LMX and OID have been extensively investigated, but little has been known about the relationship between the two. A recent study found that the quality of leader-follower relationship is crucial to reinforce employee's identification to the organization, and called for more studies to robust the linkage between them [10]. Our study not only supports the linkage between LMX and OID, but also complements and extends their work by showing that WFE is an important mediation mechanism through which LMX influences OID.

The findings of this study also provide implications for management practitioners. This study reveals that a high-quality supervisor-subordinate relationship is crucial for facilitating employees' experience of WFE and cultivating employees' identification to their organization. Therefore, appropriate selection and trainings of managers are especially important. Organizations should select supervisors based on the desirable personality traits and train their managers to reinforce quality supervisor-subordinate relationships and encourage their subordinates to apply the resources available in work domain to their family domain appropriately. 


\section{Acknowledgement}

This research was financially supported by the Humanity and Social Science Youth foundation of Ministry of Education of China (12YJC630156), and the Fundamental Research Funds for the Central Universities (D2155990), SCUT.

\section{References}

[1] J. H. Greenhaus, and G. N. Powell, When work and family are allies: A theory of work-family enrichment, Academy of Management Review, 31 (2006) 72-92.

[2] J. H. Wayne, A. E. Randel, J. Stevens, The role of identity and work-family support in work-family enrichment and its work-related consequences, Journal of Vocational Behavior, 69 (2006) 445-461.

[3] D. S. Carlson, M. K. Kacmar, J. H.Wayne, J. G. Grzywacz, Measuring the positive side of the work-family interface: Development and validation of a work-family enrichment scale, Journal of Vocational Behavior, 68 (2006) 131-164.

[4] K. Byron, A meta-analytic review of work-family interference and its antecedents, Journal of Vocational Behavior, 67 (2005) 169-198.

[5] R. C. Liden, R. T. Sparrowe, S. J. Wayne, Leader-member exchange theory: The past and potential for the future, In: G. R. Ferris (Eds.), Research in personnel and human resource management Greenwich, CT: JAI Press, 15 (1997) 47-119.

[6] R. T. Sparrowe, R. C. Liden, Process and structure in leader-member exchange, Academy of Management Review, 22 (1997) 522-552.

[7] G.B. Graen, Role making onto the starting work team using LMX leadership: Diversity as an asset, In: G.B. Graen (Eds.), LMX leadership: The series. Greenwich, CT:Information Age Publishing, 1 (2003) 1-28.

[8] B. E. Ashforth, S. H. Harrison, K. G. Corley, Identification in organizations: An examination of four fundamental questions, Journal of Management, 34 (2008) 325-374.

[9] K. J. Harris, A. R. Wheeler, K. M. Kacmar. Leader-member exchange and empowerment: Direct and interactive effects on job satisfaction, organization identification, and performance, The Leadership Quarterly, 20 (2009) 371-382.

[10] R. Loi, K. W. Chan, L. W. Lam, Leader-member exchange, organizational identification, and job satisfaction: A social identity perspective, Journal of Occupational and Organizational Psychology, 87 (2014) 42-61.

[11]H. Tang,H. Ma,B. Wang, Development of Work-family Enrichment Questionnaire and Research on Its Validity and Reliability. Chinese Journal of Clinical Psychology, 17 (2007) 430-433 [In Chinese].

[12]T. A. Scandura, G. B. Graen, M. A. Novak, When managers decide not to decide autocratically: An investigation of leader-member exchange and decision influence, Journal of Applied Psychology, 71 (1986) 579-584. 
[13] A. Carmeli, G. Gilat, D. A. Waldman, The role of perceived organizational performance in organizational identification, adjustment and job performance, Journal of Management Studies, . 44 (2007) 972-992.

[14]Preacher, K.J. and Hayes, A.F. SPSS and SAS procedures for estimating indirect effects in simple mediation models, Behavior Research Methods, 36 (2004) 717-731. 